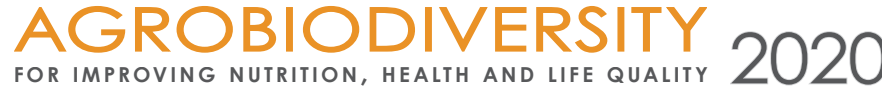

e

\section{SPECTRAL QUALITY OF SUPPLEMENTAL LED GROW LIGHT ALTERS CHILLING TOLERANCE IN ORNAMENTAL PLANTS}

\author{
Shelepova Olga*, Voronkova Tanjana, \\ Olekhnovich Ludmila, Kondratieva Vera
}

N.V. Tsitsin Main Botanical Garden of Russian Academy of Sciences, Moscow, Russia

Received: 23. 4. $2020 \quad$ Revised: 30. 6. $2020 \quad$ Published: 20. 11. 2020

The spectral properties of light changes the direction and intensity of metabolic processes in the plant, which allows it to adapt to changing environmental conditions. The influence of the spectral properties of light on plant physiology is still not fully understood, and a significant part of the research is devoted to the short-term effects of processing with monochromatic light in growth chambers. The purpose of this study was to determine whether the spectral modifications of additional LED lighting in greenhouse production can alter the characteristics of ornamental plants after growing, which is susceptible to chilling injuries. We grew snapdragons (Antirrhinum majus nanum L.) cv. Flora Shower White, tagetes (Tagetes patula L.) cv. Karmen, and multi-flowered petunia (Petunia hybrida L.) cv. Mambo blue in greenhouse conditions, using two different additional methods of irradiation with LEDs: $100 \%$ red $(\lambda=600 \mathrm{~nm})$ (RL variant) and $100 \%$ blue $(\lambda=400 \mathrm{~nm}$ ) (BL variant), followed by modeling the effect on the seedling of short-term cooling. The plants studied in the experiment are often used in urban landscaping and are exposed to low positive and zero temperatures, especially in the first days after transplanting into open ground. Morphological indicators and levels of hormonal regulators (salicylic acid (SA) and abscisic acid (ABA)) and water-soluble sugars, as well as changes in the selective permeability of cell membranes, were determined at the end of the exposure period. Light treatment showed a noticeable effect on the resistance of seedlings to cooling. Short-term exposure to low temperatures caused a violation of the semipermeability of cell membranes in all experimental variants, but it was minimal in plants under exposure to spectral light: the electrolyte yield decreased by $50 \%$ in comparison with the control in petunias, up to $37 \%$ in snapdragon and up to $37 \%$ in tagetes eighteen \%. In the test variants, after cooling, the yield of potassium ions and the content of salicylic acid decreased - by 9 and 14\% (RL) and 21, respectively, by 37\% (BL), and the content of watersoluble monosugars increased. After cooling, tagetes quickly restored turgor in the RL variant, but in the control and when using BL this process was slowed down, there was damage on the leaf edges. Plants of snapdragons and petunias under illumination (RL and BL) quickly recovered, they maintained a habitus close to the original, and budding began. In control plants, restoration proceeded more slowly; their decorative qualities were low. When transplanted into the open ground (at night temperatures of $2-5^{\circ} \mathrm{C}$ ), the survival rate of ornamental plants after exposure was $80-100 \%$ versus $60-70 \%$ in the

\footnotetext{
*Corresponding author: Olga Shelepova, N.V. Tsitsin Main Botanical Garden of Russian Academy of Sciences, Botanicheskaya, 4, 127276 Moscow, Russia shelepova-olga@mail.ru
} 
control. Additional illumination with narrow-spectrum light when growing seedlings of ornamental plants can reduce the death of plants from spring frosts.

Keywords: snapdragon, tagetes, petunia LED light, chilling injury, cell membranes, water-soluble carbohydrates, salicylic acid

\section{Введение}

Проблема повышения устойчивости декоративных растений к неблагоприятным условиям среды имеет важное научное и практическое значение. При этом одним из актуальных направлений остаются исследования, направленные на выявление механизмов адаптации растительных организмов к низким температурам. Так как низкотемпературный стресс и вызванные им повреждения растительных тканей являются одним из основных факторов ограничивающих рост растений, их продуктивность, а также распространение по климатическим зонам (Turchaninova, 2006; Trunova, 2007). Этот фактор не теряет своего значения и при озеленении городов, когда рассаду декоративных теплолюбивых растений пересаживают из оранжерейных условий в грунт. Формирование холодоустойчивости декоративных растений обусловлено различными изменениями клеточного метаболизма, в том числе увеличением содержания сахаров, синтезом стрессовых гормонов, изменением свойств мембран, процессов дыхания, фотосинтеза и др. (Tarchevsky, 2001; Avercheva et al., 2009).

В настоящее время к числу приоритетных направлений современной агробиотехнологии относится изучение механизмов регуляции роста и устойчивости растений к разным по природе неблагоприятным факторам среды под влиянием различных факторов, например, таких как узкополостный спектральный свет. Известно, что спектральный состав света меняет интенсивность и направленность метаболических процессов в растении (Olle and Viršilè, 2013; Avercheva et al., 2009). Интенсивность освещения, его продолжительность и длина волны могут вызвать экспрессию определенных генов и синтез ряда новых веществ, влияющих на генеративные органы растений (Causin et al., 2006; Vanninen et al., 2010; Colquhoun et al., 2013). Однако физиолого-биохимические основы адаптации остаются недостаточно изученными. Существует предположение, что узкоспектральный свет связан с активизацией COR генов, инициирующих синтез белков холодового стресса. В этот каскад взаимосвязанных преобразований вовлекается несколько светозависимых реакций, что существенно корректирует метаболизм растений; меняется гормональный и углеводный статус его клеток, проницаемость их мембран, активизируется или ингибируется работа отдельных ферментов (Chinnusamy et al., 2006; Crosatti et al., 2013). В этот каскад взаимосвязанных преобразований вовлекаются несколько светозависимых реакций, что существенно корректирует метаболизм растения: меняется гормональный и углеводный статус клеток, проницаемость их мембран, активируется или ингибируется работа некоторых ферментов (Kreslavsky et al., 2007; Trotta et al., 2014; Van Gelderen et al., 2018). Повышение устойчивости растений 
к гипотермии связано с подавлением окислительного стресса за счет связывания активных форм кислорода (АФК) и свободных радикалов, благодаря действию антиоксидантных ферментов и накоплению низкомолекулярных органических антиоксидантов (Pennycooke et al., 2005; Patton et al., 2007). При адаптации к холодовому стрессу растения аккумулируют стресс-протекторные вещества - аминокислоты, растворимые сахара, сахароспирты и другие метаболиты (Patton et al., 2007; Van Gelderen et al., 2018).

Высказывается мнение, что COR-гены активируются при облучении красным $(\lambda=660$ нм) и синим $(\lambda=400$ нм) светом, то есть в регуляцию экспрессии этих генов вовлекаются световоспринимающие рецепторы фитохромы и криптохромы (Crossatti et al., 1999; Zhao et al., 2014). Информация о стабилизирующем влиянии красного и синего света при регуляции экспрессии генов в стрессовых условиях позволяет предположить наличие первичных элиситорных сигналов различной природы. Адаптацию к понижению температуры моделирует ряд взаимосвязанных процессов, позволяющих растению изменить клеточный и метаболический гомеостаз (Rejeb et al., 2014). Существенную роль в работе этих каскадных механизмов играют салициловая (СК) и абсцизовая (АБК) кислоты. СК - один из метаболитов, инициирующих экспрессию генов синтеза ферментов антиоксидантной защиты, что позволяет контролировать АФК, сохранить целостность клеточных мембран и окислительно-восстановительный статус клеток растения (Janda et al., 2007; Mahdavian et al., 2008; Yuan and Lin, 2014). Накопление АБК в тканях включает АБКсигнальный каскад, который завершается экспрессией COR-генов, определяющую холодовую толерантность вида (Shi and Yang, 2014).

В представленной работе мы изучали влияние узкополосного красно-синего спектрального освещения на рост и развитие рассады декоративных растений и в дальнейшем определяли влияет ли данная подсветка на формирование устойчивости рассады к непродолжительному воздействию низких положительных температур при весенних заморозках.

\section{Материалы и методика}

\section{Объекты исследования}

В качестве объектов исследования были взяты декоративные растения, часто используемые в открытом грунте при озеленении городов - львиный зев (Antirrhinum majus nanum L.), низкорослый сорт Flora Shower White, тагетис (Tagetes patula L.), низкорослый сорт Karmen, и многоцветковая петуния (Petunia hybrida L.) сорта Mambo blue.

Растения в стадии 5 - 7-го листа высаживали в сосуды с песком (по 5 растений, в каждом варианте по 15 сосудов). Растения выращивали в следующих условиях: Контроль (1-й вариант - К) - растения, выращенные при естественном освещении. Вариант 2 - к естественному свету добавляли красный ( $\max \lambda=600$ нм) (КС) свет; вариант 3 - к естественному свету добавляли синий ( $\max \lambda=400$ нм) (CC) свет. В качестве 
дополнительных источников света использовали светодиодные лампы модели ПС-2 (УСС-12) («Фокус», Россия). Интенсивность (плотность фотонов) для КС составляла $2,58 \times 10^{18}$ и для синего $-6,04 \times 10^{18}$ фотонов $/\left(\mathrm{m}^{2} € c\right)$. Подсветку растений проводили ежедневно по 12 ч. Полив дистиллированной водой осуществляли ежедневно, подкормку проводили 1 раз в неделю 150 мл питательной смесью Кнопа 0,25 г фосфата калия, 0,25 г сульфата магния, 1 г кальциевой селитры и 0,125 г хлористого калия на 1 л дистиллированной воды). После окончания подсветки половину растений из каждого варианта (КС, СС, К) помещали на 24 ч в камеру с температурой $2{ }^{\circ} \mathrm{C}$, оставшиеся растения оставляли без охлаждения. Пробы для биохимических анализов брали на 35-й (после окончания подсветки) и 37-й день (на 2-й день после воздействия холодового стресса).

\section{Определение функционального состояния мембран}

Для определения функционального состояния мембран клеток навеску листьев 0,3 г помещали в бидистиллят, выдерживали 24 ч в термостате при температуре $26{ }^{\circ} \mathrm{C}$ и измеряли электропроводность элюата, определяли в нем содержание ионов $\mathrm{K}^{+}$ потенциометрически с использованием ионоселективных электродов (ИТАН, ООО «НПП «Томьаналит»», Россия); ионоселективный электрод Элит-031, ООО «НИКО Аналит», Россия) по ранее опубликованной методике (Kondratieva et al., 2011).

\section{Определение содержания сахаров}

Содержание моносахаров определяли спектрофотометрически (Specol 1300, «Analytik Jena AG», Германия) с помощью пикриновой кислоты (Kondratieva et al., 2008). Количество салициловой (СК) и абсцизовой (АБК) кислот анализировали из одной навески: 2 г сырых листьев экстрагировали этанолом (80 \%), экстракт упаривали до водной фазы, которую делили на две равные по объему части. Для выделения СК и АБК экстракт очищали по модифицированной в лаборатории методике (Shelepova et al., 2012). На заключительном этапе использовали изократическую высокоэффективную жидкостную хроматографию (изократический хроматограф Стайер, ЗАО «Аквилон», Россия) с колонкой RP-18 (250/4,6 мм) («Phenomenex, Inc.», США).

\section{Статистические методы}

Статистическую обработку данных проводили с применением программы PAST v3.0 (Hammer et al., 2001). Определяли средние значения изучаемых показателей $(M)$, стандартные ошибки средних $( \pm$ SEM) и доверительный интервал при $95 \%$ доверительном уровне $\left(t_{0,05} \pm \mathrm{SEM}\right)$. Достоверность различий между вариантами оценивали в программе PAST v3.0 методом непараметрической (критерий парных сравнений Шапиро-Уилкоксона) статистики. Различия между вариантами считали достоверными при $p \leq 0,05$.

\section{Результаты и дискуссия}

Перепады суточных температур в весенний и осенний периоды часто вызывают повреждения и даже гибель растений. Температура, использованная нами для 
моделирования холодового стресса $\left(2^{\circ} \mathrm{C}\right)$, не летальна для изучаемых растений, но может вызвать существенные повреждения листьев (Petrovskaya-Baranova, 1983).

После окончания подсветки КС и СС светом особых различий по габитусу и морфологии у тагетиса по вариантам не было. И в опыте, и в контроле отмечали хороший тургор листьев, почти у 30 \% растений началась бутонизация. У тагетиса, львиного зева и петунии после подсветки КС увеличилась биомасса надземной части растений (соответственно в 1,2, 1,3 и 1,6 раза) и корней (в 1,5; 1,2 и 1,8 раза) по сравнению с контролем (Рисунок 1). А после подсветки СС у всех трех видов декоративных растений увеличилась биомасса корней - в 1,8 раза у тагетиса и в 2,2 раза у львиного зева и петунии. Сроки начала цветения в опытных вариантах не отличались от таковых в контроле, но продуктивность цветения возросла на 19-23 \% по сравнению с контролем. В мае при пересадке в открытый грунт (при дневной температуре $10-12{ }^{\circ} \mathrm{C}$ и ночной $2-5{ }^{\circ} \mathrm{C}$ ) приживаемость растений в вариантах КС и СС была от $100 \%$ (тагетис, петуния) до 80 \% (львиный зев), тогда как у контрольных растений она составила $60-70 \%$.

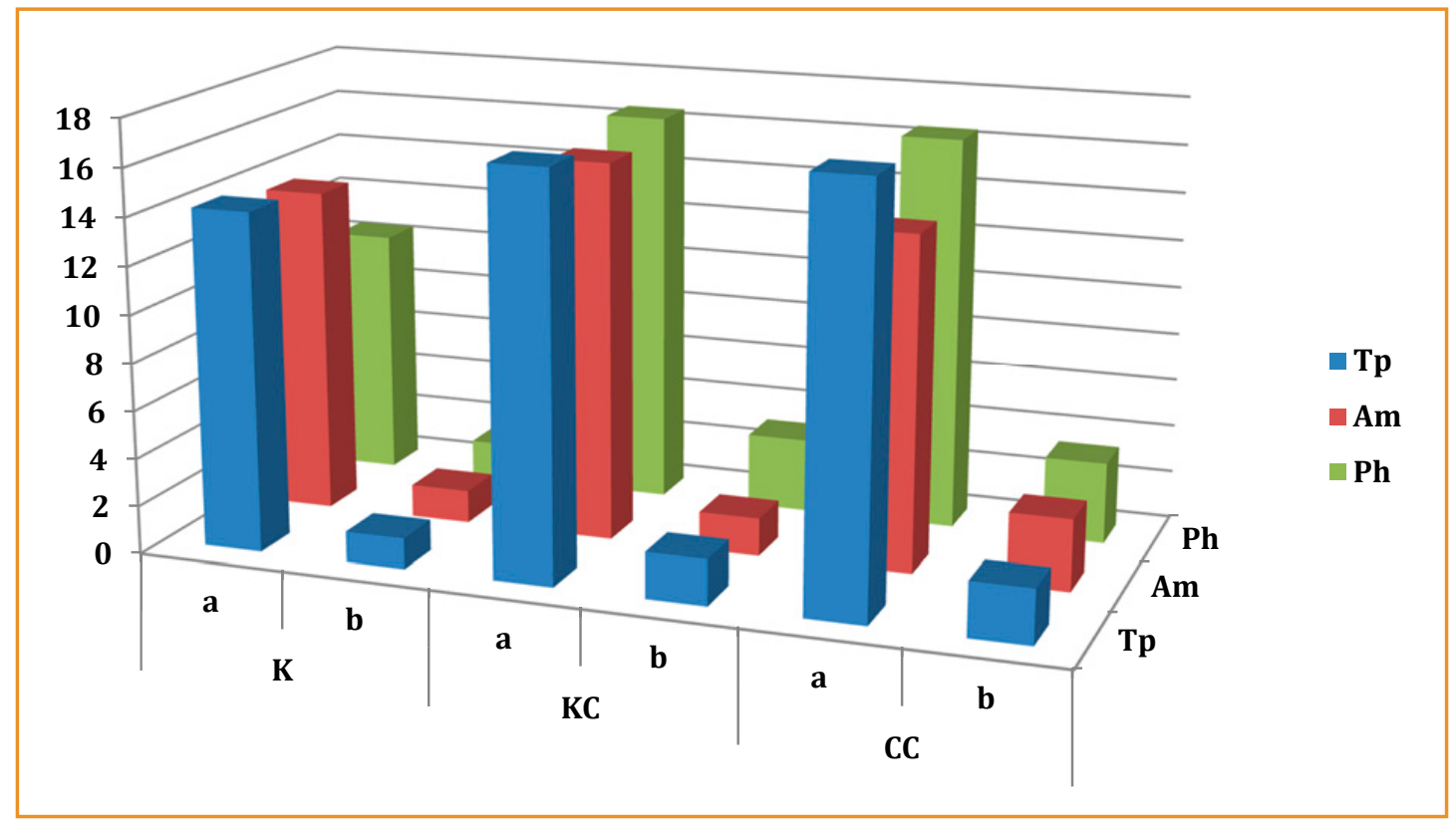

Рисунок 1 Влияние разных видов подсветка узкоспектральным светом на биомассу растений (г) варианты опыта - К (контроль); КС (красный свет); СС (синий свет). а - надземная часть растений; b - корни растений. Тр - тагетис (Tagetes patula L.), сорт Karmen; Am - львиный зев (Antirrhinum majus nanum L.), сорт Flora Shower White; Ph - петуния (Рetunia hybrida L.), сорт Mambo blue

Figure 1 The influence of different types of illumination by LED light on the biomass of plants ( $\mathrm{g}$ ) experimental options - K (control); KC (red light); CC (blue light). a - aerial part of plants; b - plant roots. $\mathrm{Tp}$ - tagetes (Tagetes patula L.), cultivar Karmen; Am - snapdragon (Antirrhinum majus nanum L.), cultivar Flora Shower White; $\mathrm{Ph}$ - petunia (Petunia hybrida L.), cultivar Mambo blue

Важным показателем стрессоустойчивости растений служит состояние мембранной системы клеток листьев. Сохранение избирательной проницаемости плазмалеммы 
для некоторых ионов и для молекул воды позволяет поддерживать гомеостаз клеток (Tarchevsky, 2001). Для его coхранения в клетке важно накопление ионов натрия в вакуоле, поддержание физиологической концентрации ионов калия и высокого соотношения $\mathrm{K}+/ \mathrm{Na}+$ в цитоплазме (Munns and Tester, 2008), то есть увеличение выхода ионов калия указывает на негативные изменения во внутренней среде клетки. В тканях листьев у тагетиса после окончания досветки избирательная проницаемость мембран снизилась в варианте КС $(27,4 \mu \mathrm{Cm} /$ мл) и осталась в пределах контроля (41,0 $\mu$ См/мл) в случае СС (40,6 $\mu$ См/мл), тогда как у растений львиного зева и петунии выход электролитов под воздействием КС возрос по сравнению с контролем незначительно (на 4,4 и 2,2 (на 24,5 и 10,3 $\mu$ См/мл, соответственно). При этом выход ионов калия существенно снизился в обоих вариантах опыта относительно контроля, что позволило сохранить высокое соотношение $\mathrm{K}^{+} / \mathrm{Na}^{+}$в цитоплазме клеток растений, подвергавшихся подсветке (Рисунок 2).

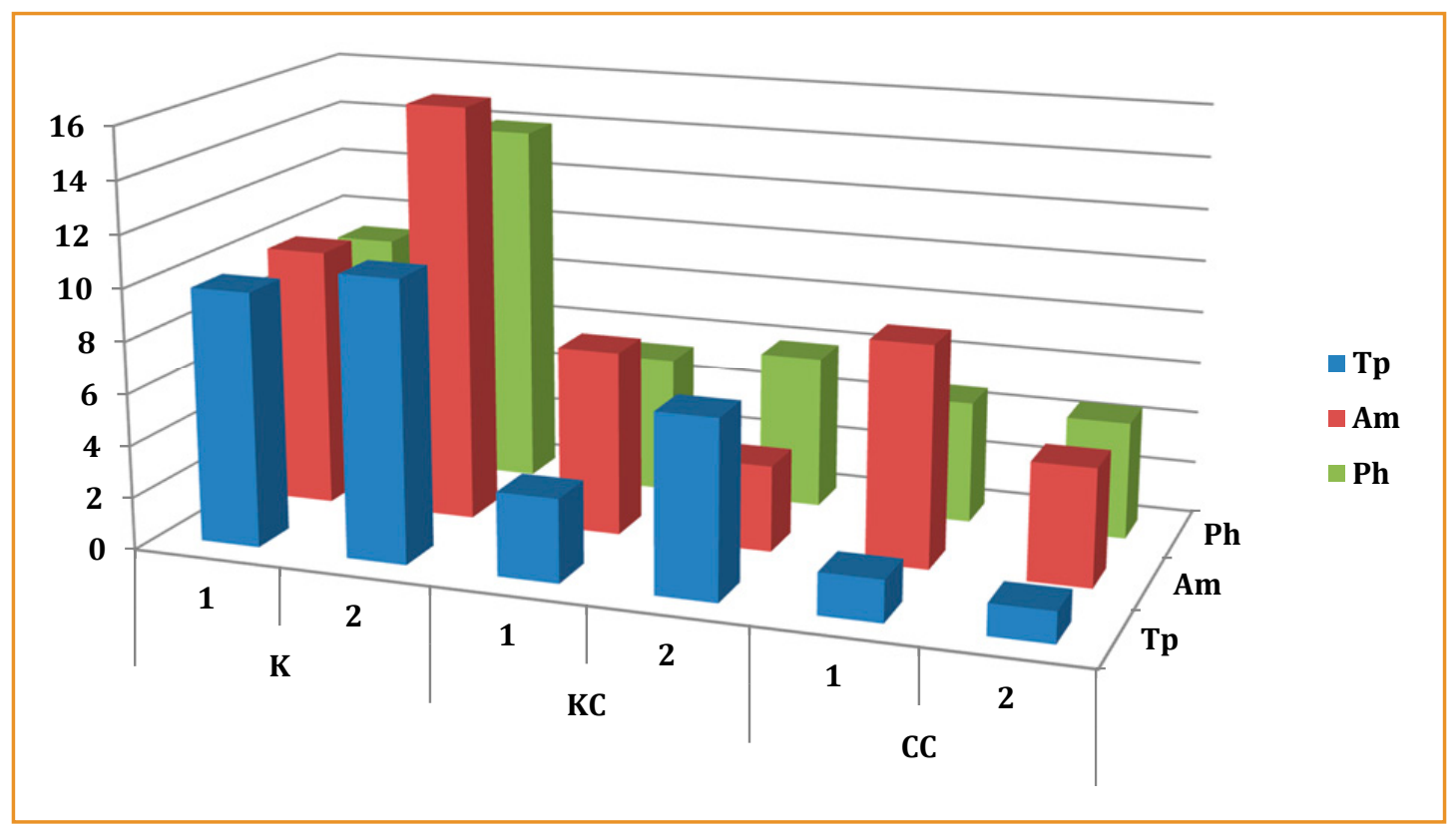

Рисунок 2 Влияние разных видов подсветки узкоспектральным светом на проницаемость клеточных мембран растений (выход ионов калия, мкг/мл): варианты опыта - К (контроль); КС (красный свет); СС (синий свет)

1 - показатель на момент завершения подсветки; 2 - показатель после воздействия холодового стресса. Tр - тагетис (Tagetes patula L.), сорт Karmen; Am - львиный зев (Antirrhinum majus nanum L.), сорт Flora Shower White; Ph - петуния (Petunia hybrida L.), сорт Mambo blue

Figure 2 The influence of different types of illumination by LED light on the permeability of plant cell membranes (yield of potassium ions, $\mu \mathrm{g} / \mathrm{ml}$ )

experimental options - K (control); KC (red light); CC (blue light). 1 - Indicator at the time of completion of exposure; 2 - Indicator after exposure to cold stress. Tp - tagetes (Tagetes patula L.), cultivar Karmen; Am snapdragon (Antirrhinum majus nanum L.), cultivar Flora Shower White; Ph - petunia (Petunia hybrida L.), cultivar Mambo blue 
У всех растений воздействие низкими положительными температурами привело к нарушению полупроницаемости мембран, но в контроле оно было максимальным. Наиболее устойчивыми к кратковременному холодовому стрессу оказались растения петунии, подсвеченные КС и СС: в тканях их листьев выход электролитов снизился на 51-52 \% по сравнению с контролем, тогда как у тагетиса снижение составило 12-18 \%, а у львиного зева - 9-37 \% (Рисунок 2). При воздействии КС и особенно СС у всех растений достоверно снизился выход ионов калия. Следует отметить, что при досветке узкоспектральным светом восстановление растений после окончания холодового стресса шло быстрее, особенно в варианте КС, тогда как контрольные растения не только медленнее восстанавливались, но и снижалась их декоративная оценка.

Подсветка рассады декоративных растений узкоспектральным светом значимо не повлияла на содержание водорастворимых углеводов в тканях листьев - у всех трех декоративных растений данный показатель оставался на уровне контроля (Рисунок 3). Однако воздействие холодового стресса привело к увеличению содержания моносахаров у тагетиса, львиного зева и петунии в обоих вариантах (КС и СС) по сравнению с контролем, при этом наиболее существенно возросло (на 37 \% у петунии и на 21 и 20 \% у львиного зева и тагетиса, соответственно) содержание водорастворимых углеводов под влиянием СС. Известно, что моносахара, не только служат энергетическим ресурсом, но и играют существенную протекторную роль при сохранении гомеостаза клеток при стрессе (Trunova, 2007). Вероятно, в нашем опыте они способствовали формированию реакции растений, обеспечивающей их выживание в стрессовых условиях гипотермии.

Одним из триггеров протекторного сигнального пути служит салициловая кислота. Ее роль в запуске и регуляции адаптационного механизма неоднозначна (Yuan and Lin, 2014). Недостаток или избыток СК может вызвать усиление стрессового воздействия, так как количества СК и АФК коррелируют, а с содержанием СК связана инициация каскада защитных реакций (Mateo et al., 2006), который светозависим и действует в комплексе с другими протекторными механизмами (Bechtold et al., 2005). У всех растений после окончания подсветки количество СК возросло по сравнению с контролем, наиболее существенно - под влиянием КС у тагетиса (на 223 \% по сравнению с контролем) (Рисунок 4). По-видимому, в этом случае начал меняться гормональный баланс в тканях листьев и, как следствие, перестраивался весь метаболизм растений. После холодового стресса содержание СК у растений тагетиса в обоих вариантах снизилось как по сравнению с контролем (на 29-61 \%), так и относительно показателей до воздействия холодового стресса: в варианте КС - в 2,3 раза, СС - в 2,0 раза. У растений львиного зева и петунии после окончания подсветки КС и СС содержание СК значимо не изменилось по сравнению с контролем. Воздействие холодового стресса на подсвеченные КС и особенно СС растения обоих видов привело к увеличению содержания СК - на 9 и 14 \% (вариант КС) и на 21 и 37 \% (вариант СС) соответственно у львиного зева и петунии. 
Shelepova, O., Voronkova, T., Olekhnovich, L., Kondratieva, V.

Agr.bio.div. Impr. Nut., Health Life Qual., 2020, 23-34

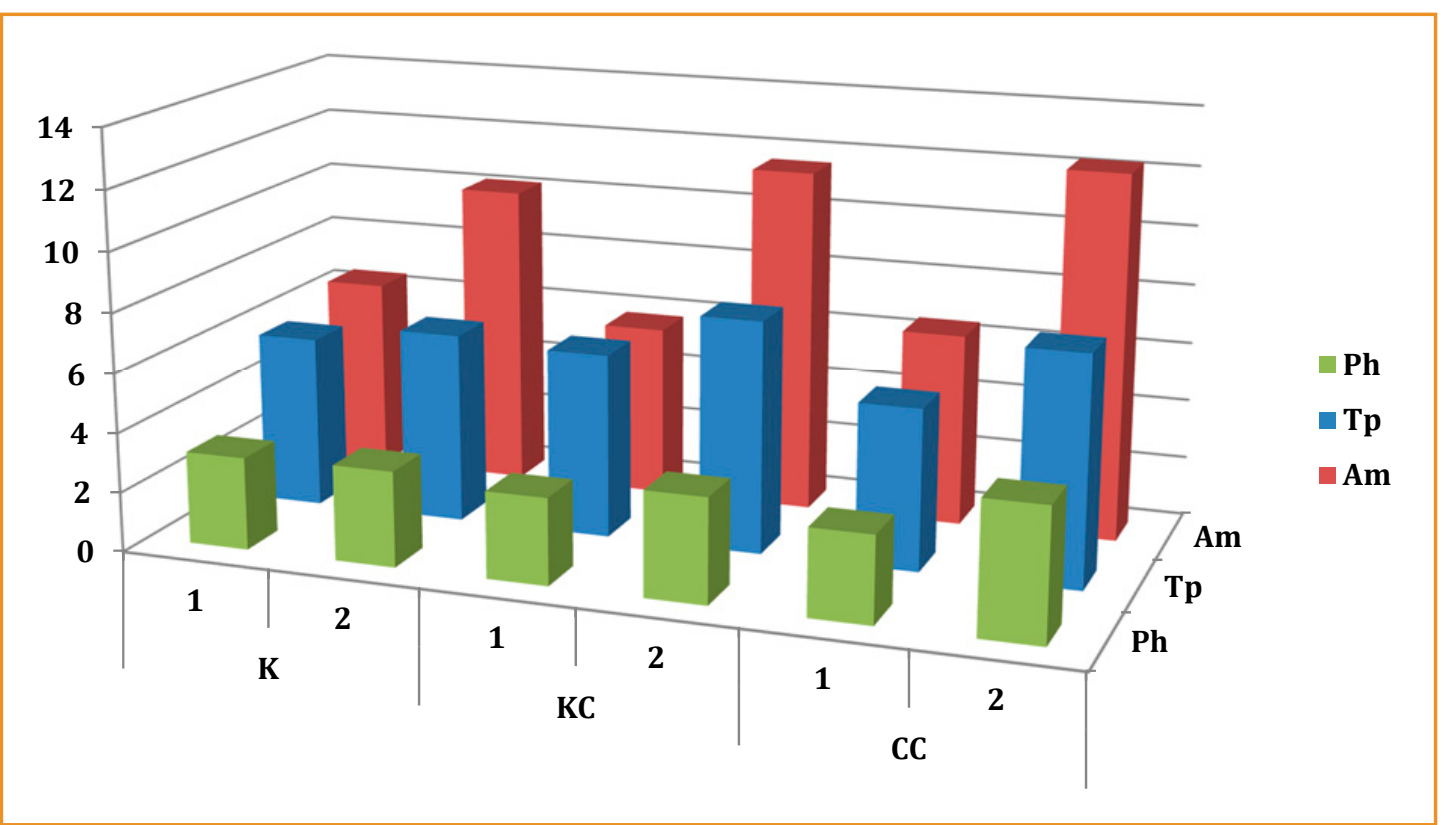

Рисунок 3 Влияние разных видов подсветки узкоспектральным светом на содержание совободных моносахаров (мкг/мг сухого вещества)

варианты опыта - К (контроль); КС (красный свет); СС (синий свет). 1 - показатель на момент завершения подсветки; 2 - показатель после воздействия холодового стресса. Тр - тагетис (Tagetes patula L.), сорт Karmen; Am - львиный зев (Antirrhinum majus nanum L.), сорт Flora Shower White; Ph петуния (Petunia hybrida L.), сорт Mambo blue

Figure 3 The influence of different types of illumination by LED light on on the content of free monosugars $(\mu \mathrm{g} / \mathrm{mg}$ dry matter)

experimental options - K (control); KC (red light); CC (blue light). 1 - indicator at the time of completion of exposure; 2 - indicator after exposure to cold stress. Tp - tagetes (Tagetes patula L.), cultivar Karmen; Am snapdragon (Antirrhinum majus nanum L.), cultivar Flora Shower White; Ph - petunia (Petunia hybrida L.), cultivar Mambo blue

Следует отметить, что растения тагетиса при подсветке синим светом после воздействия холодового стресса быстро потеряли тургор, началось повреждение краев листьев. Растения в этом варианте опыта долго восстанавливались от повреждений, поздно зацвели, почти треть из них погибла. Менее выраженные признаки повреждений были у контрольных растений, они перенесли охлаждение лучше, но были менее декоративны (слабое ветвление, мелкие бутоны). Растения, подсвеченные красным светом, имели хороший тургор листьев, у них отмечали раскрытие цветочных бутонов. Возможно, изменение гормонального статуса тканей тагетиса при подсветке красным светом способствовало включению протекторного каскада реакций, которые нивелировали негативные последствия от охлаждения. Изменение соотношения гормонов под воздействием синего света не дало положительного эффекта. Растения львиного зева и петунии быстро восстановились после холодового стресса в обоих вариантах опыта (КС и СС): их тургор, надземная масса и габитус почти не изменились. При этом в контроле восстановление после холодового стресса у львиного зева и петунии шло медленно, снизилась масса надземных (на 15 \%) и подземных (на 
Shelepova, O., Voronkova, T., Olekhnovich, L., Kondratieva, V.

Agr.bio.div. Impr. Nut., Health Life Qual., 2020, 23-34

10 \%) органов, декоративная оценка неконтрольных растений была ниже, чем при подсветке.

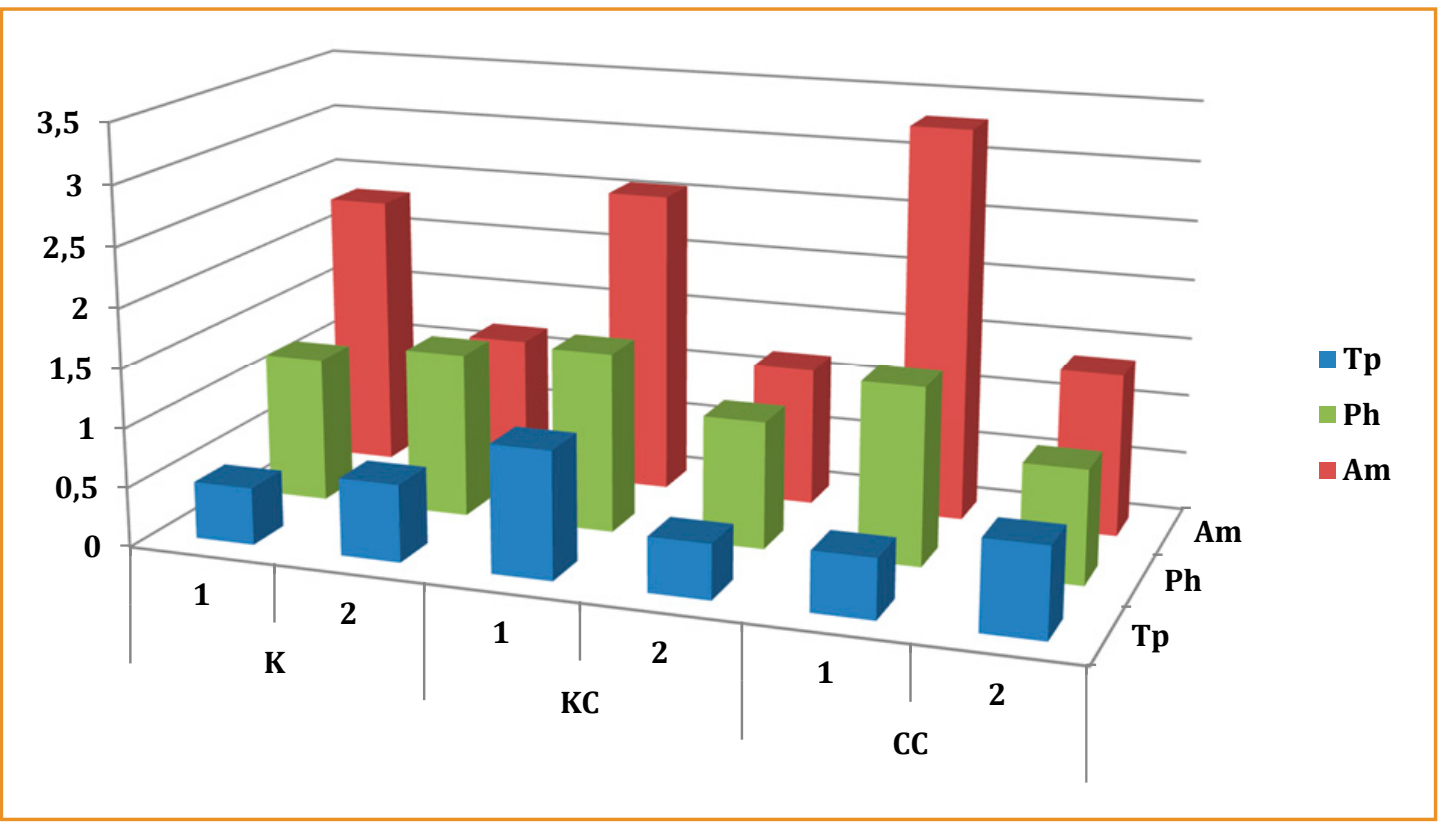

Рисунок 4 Влияние разных видов подсветки узкоспектральным светом на содержание салициловой кислоты (мкг/г сырого вещества)

варианты опыта - К (контроль); КС (красный свет); СС (синий свет). 1 - показатель на момент завершения подсветки; 2 - показатель после воздействия холодового стресса. Тр - тагетис (Tagetes patula L.), сорт Karmen; Am - львиный зев (Antirrhinum majus nanum L.), сорт Flora Shower White; $\mathrm{Ph}$ - петуния (Petunia hybrida L.), сорт Mambo blue

Figure 4 The influence of different types of illumination by LED light on the content of salicylic acid $(\mu \mathrm{g} / \mathrm{g}$ of flabby matter)

experimental options - K (control); KC (red light); CC (blue light). 1 - indicator at the time of completion of exposure; 2 - indicator after exposure to cold stress. Tp - tagetes (Tagetes patula L.), cultivar Karmen; Am - snapdragon (Antirrhinum majus nanum L.), cultivar Flora Shower White; Ph - petunia (Petunia hybrida L.), cultivar Mambo blue

В инициацию каскадных реакций, формирующих ответ на абиотический стресс, также вовлечена абсцизовая кислота (Shi and Yang, 2014). Этот гормон определяли только в тканях растений тагетиса. После окончания подсветки содержание АБК в тканях растений возросло под влиянием КС (до 0,191 $\pm 0,02$ мкг/г) и несколько снизилось (до 0,037 $\pm 0,005$ мкг/г) в случае СС по сравнению с контролем $(0,043 \pm 0,003$ мкг/г). После воздействия холодового стресса количество АБК в тканях листьев в варианте СС существенно увеличилось по сравнению с исходным $(0,066 \pm 0,008$ мкг/г), в контроле почти не изменилось $(0,048 \pm 0,004$ мкг/г), а при подсветке красным светом - снизилось в 5 раз (до 0,038 $\pm 0,004$ мкг/г). То есть эти результаты также свидетельствуют в пользу нашего предположения об изменении гормонального баланса в тканях листьев тагетиса при подсветке и, как следствие, о перестройке всего метаболизма растений. 
Возможно, свет различного спектрального состава включал разные пути активации протекторных механизмов. Триггерную функцию в такой активации могут выполнять и СК, и АБК, их сигнальные пути частично перекрываются. Формируется информационная сеть с антагонистическими и синергическими звеньями (Trunova, 2007). Возможно, в случае СС салициловая кислота способствовала быстрому переключению метаболических процессов на адаптационный режим, а при подсветке красным светом этот механизм мог включаться после выброса АФК, и салициловая кислота не вовлекалось в экспрессию защитных генов.

\section{Выводы}

Совокупность физиологических и биохимических изменений в тканях листьев декоративных растений (габитус, морфология, накопление биомассы, выход электролитов, содержание ионов калия, салициловой и абсцизовой кислот, суммы свободных моносахаров) позволяет сделать вывод, что подсветка спектральным светом способствует началу перестройки метаболических процессов и активации неспецифических протекторных механизмов, сохраняющих ионный и окислительновосстановительный гомеостаз клеток. Показано, что подсветка рассады узкоспектральным светом позволила этим растениям успешно адаптироваться к кратковременному воздействию низких температур. При пересадке в открытый грунт (в условиях ночной температуры 2-5 ${ }^{\circ} \mathrm{C}$ ) их приживаемость после подсветки составила 80-100 \% против 60-70 \% в контроле. Следовательно, добавление узкоспектрального света от светодиодных панелей к естественному освещению при выращивании рассады декоративных растений позволит снизить их гибель от резкой смены условий обитания при использовании для озеленения территорий.

\section{Благодарность}

Исследование выполнено в рамках ГЗ ГБС РАН (тема № 118021490111-5).

\section{Литература}

AVERCHEVA, O.V., BERKOVICH, YU.A., EROKHIN, A.N., ZHIGALOVA, T.V., POGOSYAN, S.I., SMOLYANA, S.O. 2009. Osobennosti rosta $\mathrm{i}$ fotosinteza rastenij kitajskoj kapusty pri vyrashchivanii pod svetodiodnymi svetil'nikami [Features of the growth and photosynthesis of Chinese cabbage plants when grown under LED lights] In Plant physiology, vol. 56(1), p. 17-16. [In Russian].

BECHTOLD, U., KARPINSKI, S., MULLINEAUX, P. 2005. The influence of the light environment and photosynthesis on oxidative signaling responses in plant-biotrophic pathogen interaction. In Plant Cell \& Environment, vol. 28, p. 1046-1055. https://doi. org/10.1111/j.1365-3040.2005.01340.X

CAUSIN, H.F., JAUREGUI, R.N., BARNEIX, A.J. 2006. The effect of light spectral quality on leaf senescence and oxidative stress in wheat. In Plant Sci., vol. 171(1), p. 24-33. https://doi.org/10.1016/j. plantsci.2006.02.009

CHINNUSAMY, V., ZHU, J., ZHU, J.-K. 2006. Gene regulation during cold acclimation in plants. In Physiologia Plantarum, vol. 126(1), p. 52-61. https://doi.org/10.1111/j.1399-3054.2006.00596.X

COLQUHOUN, T.A., SCHWIETERMAN, M.L., GILBERT, J.L., JOWORSK,I E.A., LANGER, K.M., JONES, C.R., RUSHING, G.V., HUNTER, T.M., OLMSTED, J., CLARK, D.G., FOLTA, K.M. 2013. Light modulation of 
volatile organic compounds from petunia flowers and select fruits. In Postharvest Biology and Technology, vol. 86, p. 37-44. https://doi.org/10.1016/j.postharvbio.2013.06.013

CROSSATTI, C., POLVERINO DE LAURETO, P., BASSI, R., CATTIVELLI, L. 1999. The interaction between cold and light control the expression of the cold regulated barley gene cor14b and the accumulation of the corresponding protein. In Plant Physiol., vol. 199, p. 571-599. https://doi. org/10.1104/pp.119.2.671

CROSATTI, C., RIZZA, F., BADECK, F.W., MAZZUCOTELLI, E., CATTIVELLI, L. 2013. Harden the chloroplast to protect the plant. In Physiologia Plantarum, vol. 147(1), p. 55-63. https://doi. org/10.1111/j.1399-3054.2012.01689.x

HAMMER, O., HARPER, D.A.T., RYAN, P.D. 2001. PAST: Palaeontological Statistics software package for education and data analysis. In Palaeontologia Electronica, vol. 4(1), 9 p.

JANDA, T., HORVÁTH, E., SZALAI, G., PÁLDI, E. 2007. Role of salicylic acid in the induction of abiotic stress tolerance. In Hayat S., Ahmad A. (eds) Salicylic Acid: A Plant Hormone. Springer, Dordrecht, p. 91-150. https://doi.org/10.1007/1-4020-5184-0 5

KONDRATIEVA, V.V., SEMENOVA, M.V., VORONKOVA, T.V., SHELEPOVA, O.V. 2011. Izmenenie nekotoryh fiziologo-biohimicheskih harakteristik tkanej pochki vozobnovleniya tyul'pana Ejhlera (Tulipa Eichleri Regel) $\mathrm{v}$ processe zimovki [Changes in some physiological and biochemical characteristics of the kidney tissue of the renewal of Eichler's tulip (Tulipa Eichleri Regel) during the wintering process]. In Scientific statements of Belgorod State University (Natural Sciences), vol. 3(98), no. 14/1, p. 339-345. [In Russian].

KONDRATIEVA, V.V., VORONKOVA, T.V., SHELEPOVA, O.V., OLEKHNOVICH, L.S. 2008. Physiological and biochemical aspects of clary (Salvia sclera L.) overwintering in central Russia. In Biology Bulletin, vol. 35(3), p. 255-261. https://doi.org/10.1134/S1062359008030059

KRESLAVSKY, V.D., CARPENTER, R., KLIMOV, V.V., MURAT, N., ALLAHVERDIEV, S.I. 2007. Molekulyarnye mekhanizmy ustojchivosti fotosinteticheskogo apparata $\mathrm{k}$ stressu [Molecular mechanisms of resistance of the photosynthetic apparatus to stress]. In Biological membranes, vol. 24(3), p. 195-217. [In Russian].

MAHDAVIAN, K., KALANTARI, H.M., GORBANLI, M. 2008. Vliyanie salicilovoj kisloty na formirovanie okislitel'nogo stressa, inducirovannogo UF-svetom v list'yah perca [Effect of salicylic acid on the formation of oxidative stress induced by UV light in pepper leaves]. In Plant physiology, vol. 55(4), p. 620-623. [In Russian].

MATEO, A., FRUNK, D., MÜHLENBOCK, P., KULA,R B., MULLINEAUX, P.M., KARPISNKI, S. 2006. Controlled levels of salicylic acid and required for optimal photosynthesis and redox homeostasis. In J. Exp. Bot., vol. 57(8), p 1795-1807. https://doi.org/10.1093/jxb/erj196

MUNNS, R., TESTER, M. 2008. Mechanisms of salinity tolerance. In Annu. Rev. Plant Boil., vol. 59, p. 651-681. https://doi.org/10.1146/annurev.arplant.59.032607.092911

OLLE, M., VIRŠILĖ, A. 2013. The effect of light emmiting diode lighting on greenhouse plant grows and quality. In Agricultural and Food Science, vol. 22(2), p. 223-234. https://doi.org/10.23986/ afsci.7897

PATTON, A.J., CUNNINGHAM, S.M., JOLENEC, J.J., REICHER, Z.J. 2007. Difference in freeze tolerance of zoysiagrasses. II. Carbohydrate and proline accumulation. In Crop Sci., vol. 47(5), p. 2170-2181. https://doi.org/10.2135/cropsci2006.12.0784

PENNYCOOKE, J.C., COX, S., STUSHNOFF, C. 2005. Relationship of cold acclimation, total phenolic content and antioxidant capacity with chilling tolerance in petunia (Petunia $1 / 2$ hybrida). In Environ. Exp. Bot., vol. 53(2), p. 225-232. https://doi.org/10.1016/j.envexpbot.2004.04.002

PETROVSKAYA-BARANOVA, T.P. 1983. Fiziologiya adaptacii i introdukciya rastenij. [Physiology of adaptation and introduction of plants]. M.: Nauka, 450 p. [In Russian]. 
REJEB, I.B., PASTOR, V., MAUCH-MANI, B. 2014. Plant responses to simultaneous biotic and abiotic stress: molecular mechanisms. In Plants, vol. 3(4), p. 458-475. https://doi.org/10.3390/ plants3040458

SHELEPOVA, O.V., KONDRATIEVA, V.V., VORONKOVA, T.V., OLEHNOVICH, L.S., ENINA, O.L. 2012. Fiziologo-biohimicheskie aspekty dlitel'nogo vozdejstviya na rasteniya myaty sveta neizmennogo spektral'nogo sostava [Physiological and biochemical aspects of prolonged exposure to mint light plants of an unchanged spectral composition]. In Bulletin of the Main Botanical Garden, vol. 2, p. 68-73. [In Russian].

SHI, Y., YANG, S. 2014. ABA regulation of cold stress response in plants. In Zhang D.-P. (ed) Abscisic Acid: Metabolism, Transport and Signaling. Springer, Dordrecht, p. 337-363. https://doi. org/10.1007/978-94-017-9424-4 17

Tarchevsky, I.A. 2001. Metabolizm rastenij pri stresse [Plant metabolism under stress]. Kazan, 448 p. [In Russian].

TROTTA, A., RAHIKAINEN, M., KONERT, G., FINAZZI, G., KANGASJÄRVI, S. 2013. Signalling crosstalk in light stress and immune reactions in plants. In Philosophical Transactions of the Royal Society B: Biological Sciences, vol. 369(1640), no. 2013.0235. https://doi.org/10.1098/rstb.2013.0235

TRUNOVA, T.I. 2007. Rastenie i nizkotemperaturnyj stress [Plant and low temperature stress]. M.: Nauka, 57 p. [In Russian].

TURCHANINOVA, V.V. 2006. Izuchenie termogeneza u rastenij pri nizkotemperaturnom stresse : avtoref. dissertacionnoj raboty [The study of thermogenesis in plants under low temperature stress : Abstract of dissertation theses]. Irkutsk, 16 p. [In Russian].

VANNINEN, I., PINTO, D.M., NISSINEN, A.I., JOHANSEN, N.S., SHIPP, L. 2010. In the light of new greenhouse technologies: 1. Plant-mediated effects of artificial lighting on arthropods and tritrophic interactions. In Annals of Applied Biology, vol. 157(3), p. 393-414. https://doi. org/10.1111/j.1744-7348.2010.00438

VAN GELDEREN, K., KANG, C., PIERIK, R. 2018. Light signaling, root development, and plasticity. In Plant Physiol., vol. 176(2), p. 1049-1060. https://doi.org/10.1104/pp.17.01079

YUAN, S., LIN, H.-H. 20014. Role of salicylic acid in plant abiotic stress. In Zeitschrift fur Naturforschung C, vol. 63(5-6), p. 313-320. https://doi.org/10.1515/znc-2008-5-601

ZHAO, Y., ZHOU, J., XING, D. 2014. Phytochrome B-mediated activation of lipoxygenase modulates an excess red light-induced defense response in Arabidopsis. In J. Exp. Bot., vol. 65(17), p. 4907-4918. https://doi.org/10.1093/jxb/eru247 